\title{
Comunicación y discurso de un programa televisivo. Interacción en los mensajes de móviles a un debate nocturno
}

\section{Communication and discourse in a television program. SMS}

\section{interaction with a late night talk show}

\author{
Mercedes Román Portas. Universidad de Vigo \\ Daniel Martí Pellón. Universidad de Vigo
}

Recibido: 3-III-2011 - Aceptado: 19-X-2011

Resumen:

La construcción del discurso desde el programa de debate "El gato al agua” presta el caso para investigar la evolución de los públicos hacia las comunidades de espectadores. Sobre una muestra de programas, se estudia la propuesta de temas que se hace con la entrevista a un invitado y el debate con cinco tertulianos durante la noche de la cadena digital terrestre Intereconomía TV. Durante el programa se emiten unos doscientos de mensajes que se toman como cata del acuerdo y de la interactividad con los temas del programa desde los mensajes publicados por esa porción del medio millón de telespectadores que tiene "El gato al agua". El objetivo de esta observación y análisis es comparar las manifestaciones textuales con la caracterización de los públicos y también con las descripciones de comunidades en la audiencia habitual de un programa televisivo. El mensaje telefónico de texto (SMS) acota un campo, seleccionado por la dirección del programa, pero muestra la comunicación con los temas y además permite ver diálogos paralelos al discurso del programa que manifiesta comunidades diferentes, más amplias o no, pero autónomas en sus intereses a los que la dirección del programa debe atender para mantenerlos como públicos. Esta fase de comunicación telefónica intermedia entre la llamada y la conexión en directo con plataformas digitales puede prestar experiencias para la gestión de comunidades de espectadores en línea con diferencias en la recepción e interacción con los programas.

Palabras clave:

Comunicación televisiva, públicos de medios, entrevista televisiva, debate televisivo, análisis del discurso mediático, comunidades de programas mediáticos

\section{Abstract:}

The construction of the discourse from the talk show "El gato al agua" renders the case to investigate the evolution of the public to the communities of viewers. On a sample of programs studied the proposal of topics from a guest interview and a debate with five commentators during the late night of a digital terrestrial network. During the program are issued two hundred of messages that are taken as sample of the agreement and interactivity with the agenda items from that portion of the half million viewers of the debate. The aim of this observation and analysis is to compare the textual manifestations of the public and the descriptions of communities in the usual audience of a television program. The phone message (SMS) narrows a field selected by the direction of the program, but it shows the internal communication but also some parallel discourses manifesting different communities in the program audience. Program management must attend to keep them as public. Between the telephone call and direct connections with digital platforms we can provide experiences of messages to television programs for online management of virtual communities.

Keywords:

Television communication, media publics, television interview, television debate, media discourse analysis, media social networks. 


\section{Introducción}

Como escenario de la relación entre un programa y su público se contempla la migración de la audiencia desde medios industriales de comunicación hacia multiplataformas digitales. Un momento tecnológico en el que la audiencia televisiva ya dispone de una oferta más amplia y segmentada de canales digitales terrestres, entre otras opciones. Los discursos de oposiciones y de minorías, de contenido político, religioso, pueden acceder más fácilmente a medios o programas de su perfil en cadenas o grupos de comunicación específicamente segmentados hacia ellos como público. ¿Podemos encontrar en estos medios de comunicación o canales específicos una comunicación comparable a la comunitaria, crítica o alternativa? En los espacios públicos para minorías que aparecen como alternativos durante el apogeo industrial de los medios de masas se generó una comunicación participativa mediada por profesionales. La fragmentación del sistema industrial en los canales digitales terrestres se enfrenta a una nueva adaptación a las multiplataformas en internet. iSe perciben algunos cambios en la comunicación de los públicos mediáticos que los aproxime a las comunidades o las redes sociales en internet?

Dentro de las reflexiones sobre el discurso de la audiencia se enmarca la comunicación de un programa de televisión con su público y los mensajes de respuesta al programa. Este artículo refleja una investigación de la recepción televisiva en un momento en que las respuestas del público se reciben por mensajes de móvil. El análisis del discurso desde el programa con el público, a través de esta tecnología de comunicación, se estudia como un periodo intermedio entre las prácticas de recepción doméstica de televisión generalista y otras formas de comunicación con los programas desde las plataformas digitales.

Las transformaciones de las audiencias en públicos ha sido tratada por la disciplina de la comunicación (Livingstone, 2005: 20), también interesada en la investigación de tertulias y debates públicos en radio y en televisión. Hasta cierto punto se puede considerar la participación en programas de radio y televisión como una etapa previa a interacciones más complejas entre los medios y sus comunidades de espectadores en plataformas digitales.

Tanto en los estudios sobre políticas y gestión de los medios de comunicación como en los estudios del consumo y de recepción, los públicos representan categorías clave. Incluso para los estudios de las relaciones desde organizaciones de comunicación también los públicos son conceptos fundamentales (Míguez, 2010: 163). A partir de internet aparecen otras formas de comunicación con los programas y últimamente se recuperan términos como comunidad o redes sociales para delinear nuevos alcances sociales de la mediación que los grupos de comunicación llevan a cabo desde plataformas digitales (Averweg, Leanin, 2011: 23-24). 


\subsection{Un caso: la noche de debate en Intereconomía TV}

El programa de debate "El gato al agua", una producción propia de bajo coste, ocupa tiempos y protagonistas destacados, tanto en las radios como en la franja más publicitaria de los canales españoles de televisión terrestre. Un signo de cambio del prime time espectacular hacia formatos de infoentertainment. El talk show conserva todo su carácter popular como formato industria sin perder un ápice de su capacidad para convocar un perfil determinado de audiencia. Este caso se toma para comprobar signos de la eficiencia de la televisión en la construcción de sus públicos pero también para comprobar si más bien se trata de una opción de algunas comunidades que se decantan por determinados programas.

La más antigua de las tertulias políticas españolas en antena, “La Espuela”, fue creada por Carlos Dávila, Ramón Pi y Alejo García para Radio España - Cadena Ibérica en 1987; durante el segundo de los cuatro mandatos del gobierno socialista de Felipe González. Desde entonces continúa presentando su oposición a decisiones políticas y sociales de los diferentes gobiernos, en particular los socialistas. Dos años después de su fundación, interesó al proyecto empresarial de Julio Ariza para el Grupo Intereconomía (con una estructura financiera en formación antes de la crisis económica, (Almirón 2009: 251). El grupo de hecho recoge buena parte de los valores destacados en aquella tertulia como ideario explícito en la página web de Intereconomía.

"La Espuela" pasó a ser clave también para conseguir una audiencia suficiente que sostuviera y relanzara Radio Intereconomía, con la que si inicia el grupo mediático. Conservando algunos de los tertulianos anteriores, Isabel Durán mantiene hasta la actualidad la dirección del programa de radio, que continuó su andadura en este grupo de comunicación de Intereconomía desde 2004. Por entonces el socialista Rodríguez Zapatero revalida con mayoría absoluta su segundo mandato en el gobierno español. Según EGM La Espuela alcanza una audiencia media cercana a los 50.000 oyentes.

En el canal de televisión, con un formato similar se presenta "El gato al agua” dirigido por Antonio Jiménez. De nuevo un programa de debate, con invitados y público, ocupa un destacado lugar en el Prime Time de este canal del grupo Intereconomía, entre las 22 horas y 1 de la mañana ${ }^{1}$ de lunes a viernes. Desde 2005 es uno de los soportes de su audiencia televisiva nocturna. Durante estos años ha destacado en su género y franja con una media de un $2 \%$ de cuota de pantalla, por delante de programas similares en otras cadenas de TDT (según EGM alcanza unos 500.000 espectadores diarios).

Y en internet está como gruponintereconomía.com un portal más de un grupo de medios de comunicación. En enero de 2010 unas 8.000 personas se reunieron en un grupo de Facebook pidiendo “la muerte” para Intereconomía. Dos días después se crea un grupo de contestación en la misma red social para que "viva". A finales de 2011 el grupo del canal de Intereconomía TV reúne más de 40.000 seguidores y se utiliza como agenda de eventos y canal abierto con la información corporativa. El programa "El gato al agua" reúne también en Facebook, desde julio de 2010, a parte de su comunidad ha-

1 Los viernes dura dos horas, de 23:00 a 01:00 h. 
bitual en el Portal web del Grupo Intereconomía. En estos meses se han sucedido algunas decenas de grupos de contestación enfrentados a las redes oficiales de Intereconomía en Facebook, pero en ningún caso han superado los 4.000 miembros. Las comunidades en el propio portal del grupo y los grupos en Facebook han activado en los años 2010-2011 la comunicación con seguidores y detractores.

\subsection{Nuevos usos en la participación}

Desde los orígenes de la investigación de la comunicación se ha ido limitando la atribución funcionalista de poder a los medios de comunicación. El medio rey de cada época ha tenido un gran ascendiente, pero no se le puede considerar autor protagonista de una determinada opinión pública mayoritaria en una sociedad.

Siguen dominando en la actualidad, también en el ámbito de la investigación hispana (Martí 2008), los estudios sobre medios de comunicación que con tratamientos empíricos demuestran su eficiencia como opinión pública. Son más numerosos que los trabajos sobre comunicación comunitaria en minorías, de tradición frankfurtiana, que también articulan aspectos importantes de la comunidad alrededor de medios de comunicación.

Turow (2005: 111-112) demuestra que hemos atribuido un exagerado poder a la televisión como creadora de audiencias. El espectador rechaza la saturación publicitaria como evita la baja calidad de los contenidos televisivos. Se cuestiona qué contenidos son factores de esta audiencia y en qué medida no preexiste una comunidad con una relativa coincidencia con los temas y asuntos tratados en el programa. En general la investigación de comunicación śolo atribuye construcción de comunidad en casos de minorías y de medios populares (Gandy, 2000: 3).

Desde variables contextuales se ha medido la incidencia histórica y cultural en el impacto ampliado de la eficiencia mediática (Livingstone, 2005). También desde investigaciones menos socioculturales, como los estudios de recepción de medios de comunicación (Corominas 2001), se reconoce que el espectador prueba y experimenta sus vías de comunicación y apropiación del texto mediático, según prácticas que escapan al control o las previsiones de estos mismos medios de comunicación (Thompson, 2005: 13).

Desde teorías funcionalistas de los medios, deterministas de la tecnología o simplemente constructivistas, se reconocen muchas voces que en estos tiempos de cambio tecnológico destacan el poder de los públicos para construir comunidades, o específicamente comunidades de práctica o de interés, como las que siguen determinadas series o programas televisados. Aunque desde estudios culturales y críticos sólo se reconocen como comunidades las críticas o alternativas, contraculturales, autogestionarias, etc. (Downing 2001). Pero la suscripción y el agrupamiento libre en redes sociales en internet introduce una quiebra en las sólidas y modernas separaciones nocionales entre sentidos opuestos de comunidad que no son fácilmente sostenibles en la actual sociedad líquida. En principio, la comunidad virtual no se define por nin- 
gún rasgo específico de valor o de contenido (Rheingold 1996:3) sino por el compartir una plataforma desde la que puede acceder a la información de quienes comparten su información en el sistema común.

En el paso de la radio a la televisión el público de esta tertulia se ha multiplicado por diez. Pero desde el punto de vista de la participación del público, su comunicación con los oyentes ha perdido algo de la calidez y empatía que tenía conectar con un programa de radio (Meneses, 2010: 7). Y es que en la decadencia actual de la llamada telefónica mandan los más baratos mensajes de texto enviados a los programas de televisión (en España principalmente por menores de 24 años como muestran Ruiz Mafé, Sanz Blas y Talavera (2010: 128).

Pero estos mensajes vistos en la pantalla incorporan un espacio público impreso sobre la intervención en directo de presentador e invitados en un plató.

A pesar de la corta duración inicialmente prevista para esta tecnología del mensaje telefónico de texto, no se debe pasar por alto este momento de la participación de la audiencia con los medios. New Media \& Society (desde agosto de 2007) es una de las publicaciones internacionales que se ha hecho eco en sus artículos de la importancia del SMS, tanto en su incidencia en posibles redefiniciones de formatos y géneros en el medio televisivo como en cambios de la participación. Pero también cambian prácticas y sentido de los programas o medios para aquellos espectadores que deciden intervenir con sus mensajes en el directo de la emisión. Por esta vía, además, durante unos años las televisiones han contado con una fuente de ingresos complementaria a la publicidad y con una realización añadida por los mensajes de su público que finalmente emitían. Con todo ello, y sobre todo, la práctica de recepción de los espectadores televisivos ha podido conocer un tablón público con las opiniones y el modo de pensar de los compañeros de programa entre la audiencia.

Aunque en este momento ya se percibe un declive de los mensajes de texto por vía telefónica, siguen creciendo los usos de otras mensajerías, como la instantánea o la personal o el chat grupal ahora dentro de las plataformas digitales. En adelante estas serán las fuentes documentales para completar los estudios de recepción en análisis de la interacción con medios de comunicación desde las comunidades propias, en los portales de los grandes grupos, como en las comunidades en redes sociales comerciales como Facebook donde también pueden agruparse públicos en torno a informaciones y programas de los medios. En este año 2011 la mayoría de los mensajes tienen como destino páginas y grupos alojados en Facebook.

\subsection{Entre la recepción y la interacción}

Dejando de lado aspectos financieros y de realización para otros trabajos se observa un giro en la actividad de los públicos. Evoluciona desde la comunicación interpersonal pública, como la mediada por el teléfono, hasta la comunicación interpersonal y grupal, en los mensajes escritos en el muro o el chat de una red social, por ejemplo en la propia comunidad de "El gato al agua" en el portal web de Intereconomía o en sus grupos en Facebook. 
Se atribuye a clásicos talk shows, de éxito y longevos, la construcción de sus públicos (en el pensamiento funcionalista como en la tradición de la esfera pública burguesa de Habermas y otros). En estudios más recientes se aportan tesis sobre cómo los medios están institucionalizando su función mediadora (Birks, 2010: 66). La migración de audiencias de la radio a la televisión, prácticas que solapan escucha y visionado o la programación doméstica del tiempo de ocio en los espacios familiares desplazan la recepción doméstica hacia prácticas interactivas complejas. La dirección, buen hacer y constancia del medio se toman como constructores en su audiencia de un núcleo del público para una cadena entre la oferta del resto de medios (por ejemplo Turow, 2005: 11-12).

Pero además de reconocer el buen hacer de un programa, los cambios en la participación de los públicos con programas de radio y de televisión, y en concreto en tertulias y debates, se reconocen como nexos que refuerzan y construyen comunidades más allá de unos genéricos públicos (Livinsgtone y Lunt, 1991).

Una investigación sobre la actividad de estos públicos, tampoco la más extendida, se centra en el plano de cada espectador o usuario. En los estudios clásicos de mediados del s. XX la participación en los medios de comunicación del público se restringe a actividades menores, como después han explicado los estudios de recepción individual y doméstica de los contenidos mediáticos. Con internet la recepción se convierte en una actividad voluntaria y en la navegación digital no sólo se realiza una recepción meramente pasiva. La persona se implica en la búsqueda de información y en la navegación y en la comunicación a través espacios digitales. El debate intelectual se centra en sus consecuencias e implicaciones, con tensiones comparables a las de los estudios mediáticos ya que no se resuelve de modo evidente si la producción de sentido del espectador es inducida o responde a la libertad individual, como plantea Guillermo Orozco (2004: 35).

Específicamente acerca de los mensajes de texto se suscitan similares cuestiones en cuanto a su impacto en la programación de las cadenas así como en posibles cambios de percepción o incluso de sentido de los medios de comunicación en el imaginario de sus públicos habituales (Beyer, Enli, Maasø, Ytreberg, 2007: 230).

En esta migración o modificación, primero de la recepción de la tertulia de la radio a la televisada, y años más tarde, del debate en las televisiones a las plataformas digitales, el mensaje de texto ha ocupado una vía intermedia que puede modificar la participación del espectador. Quizá se trate del periodo en el que se ha transformado la recepción en interacción, o al menos el tiempo en el que se han extendido este cambio terminológico. Y contamos además con un cambio de tecnología de comunicación, el mensaje de texto o SMS, para delimitar fronteras menos borrosas en el campo de investigación, habitualmente más indefinidos en los estudios de recepciones mediáticas.

Ya con la portabilidad y ubicuidad digital en la segunda década de Internet, la llamada web 2.0, volvemos a tecnologías más variadas, sociales las llaman, que de nuevo desdibujan los márgenes de la programación y los campos de estudio, además con más opciones de participación con los medios de comunicación (Ytreberg 2009: 468). Pero cuanto más se acercan los 
programas a sus públicos, cuanto más se convierte la recepción en interacción, más se podría investir el medio de comunicación con notas o características antes consideradas exclusivas de los medios alternativos, de los medios ciudadanos o comunitarios.

\subsection{La comunicación a estudio}

No interesa el grupo español de comunicación como tal. Tampoco es un estudio de las tecnologías en la comunicación con los programas o con los medios. Incluso la misma recepción e interacción son materia de estudio en la medida en que aproximan al conocimiento de los públicos y comunidades de unos programas. Interesa la relación que un programa televisivo convierte en conocimiento y manifestación de su colectivo, público o comunidad.

Con este abanico de cuestiones en torno a la comunicación de programas televisivos no sólo interesan los estudios mediáticos y los estudios de recepción (Orozco, 1991: 41). También afectan a la investigación de la comunicación en comunidades (Gordon 2009, Jankowski 2002). Al principio, delimitadas por alcance de un medio en un territorio, internet ya extiende las agrupaciones virtuales a comunidades de interés, de intercambio, etc. (Jankowski, 2006: 65)

Otra vertiente -aún menos extendida que el criticismo- de la investigación actual se centra en los públicos. Por un lado, el constructivismo mantiene un relativo determinismo tecnológico, y atribuye a la mediación digital opciones radicales de transformación social. La investigación crítica de la comunicación digital en comunidades, también incipiente, critica ese utopismo y mantiene las prevenciones tecnológicas frankfurtianas cuando se reproducen las relaciones de poder de los medios y otras industrias culturales en la comunicación digital en internet (Pinho Neto, 2010: 6-7).

Lo que se pueda clarificar de esta nueva socialización digital es relevante. También importa revisar la percepción y la valoración de un programa por espectadores cuya actividad principal se aleja del visionado de la pantalla y se combina con otras tareas en portátiles, móviles, teclados, joy-sticks ... (Monge y Olabarri, 2011; Gutiérrez Rubí, 2011).

\section{Objetivos}

Desde la absorción de la radio que emitía “La Espuela” por Intereconomía ya se apunta la orientación que este Grupo de Comunicación quiere dar al canal económico de radio del que nace y toma el nombre. Arranca de la pequeña población de oyentes de una tertulia política consolidada en la audiencia española una década antes; una audiencia tan poco numerosa como los interesados en la radio sólo económica. A lo largo de los años que ha continuado este programa de radio no ha experimentado un crecimiento de oyentes sgnificativo con respecto al que tenía con sus fundadores en Radio España.

Sin embargo en la televisión, con un formato comparable y manteniendo algunos de los anteriores protagonistas radiofónicos, "El gato al agua" alcanza una audiencia destacada entre programas similares en canales TDT españoles en horario 
nocturno. El alto nivel de audiencia de este debate televisado se podría, en principio, atribuir tanto a la empresa como a la preexistencia de una comunidad que se convierte en público fiel de este programa de la noche. Se abre un abanico de explicaciones no excluyentes: una eficiente gestión de contenidos económicos, sociales, religiosos y políticos que se suceden en el programa, o bien, quizá también, porque se ha generado una corriente de afinidad entre comunidades que pasan a conceder su favor al programa y lo siguen con asiduidad.

Desde un punto de vista académico además interesa relacionar las características del caso de este formato con el género televisivo. La retórica de los géneros televisivos interesa en distintas dimensiones: tanto en la dimensión contenedora, en cuanto formato de producción industrial de bajo coste, así como institución cambiante reconocida por los públicos, al menos durante una época (Dafonte 2010). El género dialógico del debate, heredero de la tertulia radiofónica en el imaginario público, se vincula en la industria mediática con las formas del talk show (Museum of Broadcast Communications) en las que alcanzó el éxito como para responsabilizarse de la emisión en directo durante las noches de los días laborables.

Como género de la audiencia televisiva es un espacio en el que el sentir común de una comunidad puede aparecer en las intervenciones de los presentes en el plató o en otras formas de contacto con el programa. En la comunicación mediática puede darse una vicarización del sentir común en directores y presentadores, lo que es menos evidente en la comunicación en las redes sociales, que tienden a la horizontalidad (Mautner 2005: 812). Pero también en las comunidades digitales son importantes los influenciadores, a los que al menos se exige pronunciarse; como hacen quienes envían mensajes a programas en los medios de comunicación. La participación de una comunidad podría cambiar el sentido popular del género televisivo. Medio significa algo más propio cuando se integra sentir común y comunicaciones comunitarias, y así han venido tratando los medios la literatura comunicológica crítica.

Todas estas dimensiones y acepciones del género hablado valen tanto para la entrevista como para el debate. Y también en todas ellas el programa hablado queda abierto a sus públicos, con los que puede relacionarse en directo o a través de llamadas, mensajes, etc. Los sentidos más populares de género conllevan una asunción de valores compartidos más allá de la agenda de un programa (Livingstone, Lunt, 1991: 37 y 39).

Para llegar a conocer en profundidad una práctica televisiva, como la recepción e interacción con un programa, parece recomendable llegar a un trabajo extensivo e intensivo como lo son los de tipo etnográfico. Con el análisis en profundidad de una rica muestra documental, en sus mismos escenarios de recepción, se desentrañan con más profundidad los matices de las prácticas y la interacción mediática (Soriano, 2007). La parte negativa de estos estudios son los equipos y costes que exigen. Con todo, una metodología etnográfica, como afirma Hartmann (2008: 65), tampoco garantiza un conocimiento suficiente de los contenidos visionados y evaluados por estas comunidades de la audiencia. Esta autora expresa sus dudas sobre el conocimiento alcanzable a partir de MMS, en una crítica que podría afectar a la investigación de SMS a un programa, como es el caso que se presenta en estas líneas. 
Conocer el discurso de los invitados por lo que dicen unos días de programa, y, las opiniones de espectadores, por los mensajes emitidos durante un programa, desde luego que no supone una investigación exhaustiva de los contenidos editoriales ni de la opinión general del público. Además de reconocer el programa en su género, la muestra de contenidos de una semana del programa debe permitir una caracterización suficiente de los asuntos de interés para la dirección y para la audiencia. En esa muestra se debe dirimir la convergencia o divergencia de intereses a lo largo de la semana. Se escoge la primera semana de junio de 2010, porque las redes sociales aún no se han instaurado en los portales web de las cadenas y el SMS aún ofrecía una financiación complementaria interesante para programas de entretenimiento. Para otras resultaba un canal de comunicación en expansión cada vez más aceptado por la audiencia. En esta semana además se enfrentaban los dos primeros partidos españoles en torno a una huelga, en mitad de fuerte crisis económica y con regulaciones sociales que puede afectaban a las sensibilidades religiosas, en particular a los católicos.

A través de una muestra de contenidos se persigue conocer la dirección del programa. El análisis de los temas propuestos a lo largo de la entrevista y el debate y su seguimiento por parte de los tertulianos invitados debe definir la unidad o pluralidad editorial de los contenidos expresados en las intervenciones. Los grados de convergencia y pluralismo se miden con respecto al discurso del director-presentador del programa. Se presume que una mayoría de invitados reforzarán el estilo y las temáticas del programa. Como se llama "El gato al agua”, cuenta también con que la elección del público revalide el tipo de colaboraciones del programa seleccionando al invitado preferido. Quien se lleva el gato al agua confirma o no las expectativas de agradar al público y cierra el círculo del acierto en la orientación de las temáticas y del programa.

Una de las posibles graduaciones en las intervenciones se establece por los tiempos y la libertad que se les concede como agentes o participantes en el discurso del programa. De partida es preciso distinguir los perfiles de entrevistado, tertulianos y espectadores emisores de mensajes como agentes diferentes con sus correspondientes categorías de intervención en el discurso del programa.

Desde el punto de vista de la sucesión de discursos, el abanico temático se abre en la media hora inicial con la entrevista directamente motivada por las preguntas del director. Se trata de una conversación con un invitado que dispone de más tiempo que los otros participantes en el debate para dar una visión de la situación política y económica actual y dejar claras sus posiciones y preferencias. La entrevista no es tan corta como las que incluyen los programas de variedades y tiene un tono más serio. Tampoco es una entrevista abierta y en profundidad como el programa y formato propio de la entrevista televisiva.

La entrevista además de género estrella en la producción audiovisual de bajo coste (Hutchby, 2006) es un gancho a dos segmentos diferentes de audiencia: como género de la opinión experta puede ser todo lo abierta y variada que la dirección admita y como género espectacular atrae con famosos o conocidos a audiencias más amplias. De partida para este trabajo 
se suponía que las categorías principales de cada programa proceden de la secuencia temática entre un programa y otro. Además de los temas del momento la persona entrevistada debe presentar la mayor parte del elenco temático del programa.

Los debatientes pueden ampliar o modificar el enfoque del discurso del programa tanto si la apertura del discurso queda en la dirección, como si procede del entrevistado. Tras media hora de diálogo interpersonal y anuncios, el programa se completa en un debate entre los tertulianos habiendo oído minutos antes las preguntas y respuesta de la entrevista. Del debate se espera variedad de argumentaciones y de puntos de vista en torno a las cuestiones similares o cercanas a los temas iniciales del programa. Un discurso colectivo que en sus matices y facetas puede reflejarse con mejor definición el mosaico de matices en las heterogéneas audiencias de los grandes medios de comunicación.

El título del programa refuerza este pequeño espacio que unos cientos de espectadores utilizan para comentar algo relacionado con el programa. No se olvida que los votos del público en favor de uno o de otro tertuliano deciden la discusión y le hacen ganador del debate de esa noche, el que finalmente se lleva el gato al agua.

Como el programa premia al vencedor entre los tertulianos hay un pacto implícito con la audiencia de que el argumentario más brillante o mejor defendido será el que quede con el reconocimiento de programa interpretando la opinión del público. Los participantes en debates mantienen su reconocimiento como tarjeta para futuras invitaciones y el respaldo del público no es poco aval. Para la dirección del programa la selección de la audiencia es criterio de invitación, pero también podría ser criterio editorial y de orientación del programa. En este segundo caso, el discurso percibiría cierta interacción entre programa y espectadores según las percepciones más actuales de la comunicación mediática y además tecnológicamente mediada, en este caso por el SMS telefónico.

Otra forma de respuesta aunque menos interactiva es la votación entre dos opciones a la pregunta del programa. Algo que hoy en la comunidad del programa ya está en su web antes de la emisión. El público también está presente, al menos en el discurso institucional, en todas las ocasiones en que se le invita a votar o enviar mensajes y cuando se informa de la marcha de las respuestas. Programa y audiencia reconocen el valor económico que los mensajes tienen en la financiación o han tenido hasta las actuales fórmulas para envío de mensajes desde Internet.

El selecto grupo de comunicantes desde el otro lado de la pantalla tiene las limitaciones de los textos en el teléfono móvil, aunque ya estamos en un tiempo en que se empiezan a divulgar aplicaciones alternativas para mensajes desde internet. A pesar de sus limitaciones, los mensajes ocupan una parte de la pantalla y pueden recabar más atención cuando el discurso del programa languidece o cuando se alarga en intervenciones excesivamente largas.

Si se tratara sólo de una votación estaríamos en participaciones como las de los concursos. Pero dejando de lado los géneros del espectáculo en la televisión, destacamos los contenidos y no la cantidad de los mensajes. De nuevo el objeto es 
la participación del agente espectador en el discurso del programa. La reiteración de los temas, su amplificación emocional de posiciones ideológicas compartidas o su crítica o complementación del discurso que con anterioridad se ha planteado como propuesta del programa.

Esta participación en línea que a través de los votos a la pregunta del día y los mensajes del público sobre el mejor debatiente de ese programa de "El gato al agua" culmina en el tercer nivel de agentes del discurso desarrollado durante la primera semana de junio de 2010 por el programa.

El final del proceso de comunicación es más amplio que lo que en esta muestra se ha seleccionado. Concluir sobre el discurso de unos programas podría encerrarse en una interpretación de sus intervenciones y matices. Esto mantendría el poder del medio y la eficiencia del sentido como paradigmas aún actuales de la comunicación. Pero emisión y enunciación han dejado de ser suficientes para conservar unas audiencias y se cuestionan sus modelos de negocio en los actuales canales de televisión.

Hay un grado entre tener voz propia o limitada. Los invitados, al debate y a la entrevista, se diferencian del público por la libertad y protagonismo de su intervención. El público del programa está implícito, aludido y en offo "fuera de campo". Con derecho al voto y libertad de expresión dentro de los mensajes que se ajusten a protocolo y sean visualizados durante la emisión del programa.

Del discurso como texto o como resultado se ha pasado al discurso como acción. Y su análisis no admite quedar reducido a una categorización indicando las repeticiones más frecuentes. El contenido perfecto y matemático en los estudios de mayor apariencia científica ahora revisa cómo pasa de boca en boca, de entrevistado a debatientes y finalmente en los mensajes telefónicos de texto. Como toda investigación del proceso comunicativo tiene problemas para establecer su final. Cierto alcance de cada programa lo la audiencia que tiene. Pero su durabilidad y consistencia depende más del enriquecimiento y expansión de sus argumentos y ejemplos. La comunidad de espectadores espera encontrar razones y opiniones del tipo de programa que escoge. Pero en los nuevos medios también tiene que poder interactuar. Se demanda espacio para la aparición personal y una relativa intervención.

Los espectadores de este programa son un 1\% del universo nacional. Y sólo una mínima parte del medio millón de espectadores puede enviar un mensaje de texto que aparezca en pantalla durante las más de dos horas de emisión del programa. Además las felicitaciones y los saludos, como algunos mensajes al comienzo del programa, no construyen el discurso colectivo más allá de sentirse formando parte de una comunidad de seguidores de una línea editorial y una presentación de su preferencia.

Ningún discurso de programa televisivo ha igualado la participación de invitados y público, y los realities que más se han acercado no han sobrevivido a su propio desorden. Pero ningún programa podrá en adelante olvidar al público al otro lado de la pantalla. Compiten con múltiples reclamos de atención y experimentan más altos grados de interactividad. 
En el camino hacia las redes sociales de las cadenas y de los programas el análisis de las interacciones de sus agentes y públicos es un aprendizaje intermedio que debe destilar experiencia televisiva anterior y preparar la comunicación y la interacción con las redes sociales. Terminado este estudio encontramos en el portal de Intereconomía comunidades de los distintos programas del grupo. Redes que pueden quedar sin ofrecer una interacción deseada o incluso demandada y repetir fracasos de comunicación ya conocidos en el medio televisivo. La atención a los discursos en un programa no es el único y quizá tampoco sea el principal aprendizaje de la experiencia televisiva. Pero puede servir lecciones de lo que se hacía y decía con umbrales más bajos de interacción de públicos. Aunque era una fase previa del actual momento de las redes sociales y los medios de comunicación.

Se pueden delimitar algunas notas comunitarias de una audiencia tanto desde estudios de recepción mediática como desde estudios de interacciones digitales. Como fórmula intermedia para el reconocimiento comunitario se expone en este artículo el análisis de los mensajes de texto emitidos por el programa de televisión. Es una interacción intermedia entre el acuse de recibo medido, por ejemplo, a través de cuestionarios sobre programas, y, el análisis de trayectorias de navegación en un espacio colectivo en internet.

El análisis de mensajes de texto no sólo ocupa una etapa en los cambios de tecnología de comunicación entre las cadenas y sus audiencias. Además ofrece un campo de investigación de una modalidad de respuesta distinta a la espontaneidad del habla telefónica y con mensajes menos difusos que las dinámicas de flujos en las navegaciones colectivas. Con algo más de significado que la señal de presencia de la llamada perdida, pero con algo menos de interlocución que lo que encuentran los actuales estudios de microblog (Twitter, muro de Facebook)... en los que se percibe distanciamiento y fragmentación de las estructuras conversacionales en esta "conversación en línea" que reta actualmente a la investigación del discurso.

Se encuentran consecuencias y efectos personales en las "identidades retiales" (Verdú, 2007: 134) que suscita la participación más activa en estas prácticas comunicativas tecnológicamente mediadas. Pero son más perceptibles los alcances sociales.

Desde el recepcionismo se apunta a un mínimo común denominador del colectivo de espectadores, por ejemplo, cuando se cuentan votos o se comprueba la coincidencia temática en las respuestas a los cuestionarios sobre un programa por parte de una muestra relevante de su audiencia. Mientras, la etnografía digital prefiere interpretar las pruebas de convergencia de intereses y el capital inmaterial compartido, desde la base de registros tomados de la comunidad virtual constituida como público participante. En cierto modo, representa una evaluación intermedia del carácter comunitario del público de un programa, la constatación de las coincidencias y divergencias de los mensajes, con respecto a la agenda propuesta por el programa. Una parte de la audiencia publica de manera explícita asuntos relacionados o no con el programa, desde los mensajes del texto publicados durante la emisión del programa. En este caso se investiga si son medios de una comunidad, o se acerca a serlo aunque no sean críticos o alternativos (Jankowski, 2002). 


\section{Metodología}

Estamos en un momento de cambio de las empresas mediáticas hacia otros modelos de negocio en las industrias culturales de la sociedad de la información. La investigación sigue mirando a la recepción, pero cada vez más cerca de un escenario en el que los estudios de públicos se aproximan más a las comunidades de receptores, como participantes activos en el desarrollo y difusión de los programas difundidos por medios de comunicación social. Continúa avanzando la transformación de los estudios de recepción en investigaciones de formas más avanzadas de interacción.

En estas páginas se propone conocer el alcance de los contenidos propuestos en un debate televisado. La fuente de esta información es la misma muestra de comentarios del público sobreimpresos en la pantalla durante su emisión. Sobre ellos se aplica un análisis del discurso del programa. Este análisis debe dirimir la relación de los mensajes con la agenda propuesta por el programa a través de su dirección-presentación y los debatientes.

En la investigación española de comunicación de los últimos años crece el análisis, tanto de contenido como de discurso. De acuerdo con los resultados de Martínez-Nicolás y Saperas (2011: 119), casi igualan el número de estudios que optan por el uso del análisis de contenido (relacionado con técnicas cuantitativas), con los trabajos basados en análisis de discurso (cualitativo en su planteamiento, como el análisis de contenido, pero además también cualitativo en su desarrollo, aunque pueda completarse con alguna técnica cuantitativa en el caso de investigaciones de universos digitales).

En un programa de debate, abierto por una entrevista y cerrado con aportaciones de espectadores desde mensajes y votaciones, se manifiestan varias formas distintas de participación en el discurso colectivo. Se opta por el análisis cualitativo del discurso para contar con el habla de los públicos en su transformación hacia comunidades seguidoras de programas. Interesa tanto distinguirlos, y analizar su alcance, como ver la relación que tienen en una hipotética construcción colectiva del discurso resultante del programa.

La documentación de este estudio está formada por las transcripciones escritas de las intervenciones de presentador, debatientes y espectadores participantes por mensajes en el programa "El gato al agua" del canal de televisión del grupo Intereconomía Comunicación. Tuvo lugar los días anteriores a una propuesta de huelga de funcionarios convocada por sindicatos y con poca repercusión. Tres meses después tendría efecto como la $7^{\text {a }}$ huelga en la España democrática, también de convocatoria sindical contra el decreto ley de una reforma laboral. A un programa de actualidad política y económica como "El gato al agua" este tipo de crisis política durante una larga y profunda crisis económica, aporta un paraguas temático que puede trasladarse a lo largo de varios días y desvela el posicionamiento del programa, tanto en su dirección como en las aportaciones de sus distintos participantes a lo largo de cinco días.

Para este trabajo se han registrado y transcrito 14 horas de programa con un total de 909 SMS emitidos, las repuestas de 5 invitados especiales a las entrevistas y las intervenciones de 25 tertulianos. Los programas grabados y verbalizados co- 
rresponden a los días 1, 2, 3, 4 y 7 de junio de 2010. En este tiempo el programa registraba una audiencia entre 400.000 y 500.000 espectadores y una cuota de pantalla entre 2,45 y 2,9\% del prime time de esos días. Los mensajes publicados en la televisión durante esos programas representan una cata de 1.000 opiniones sobre un universo cercano al medio millón de espectadores. Los datos más arriba citados muestran que los interlocutores son más jóvenes en España, pero no es un recurso restringido a un segmento exclusivo de público.

A partir de las transcripciones se pretende establecer la afinidad de los mensajes del público con la orientación temática del programa. Los mensajes también expresan las posiciones personales en el diálogo socio-político más amplio. El tratamiento lingüístico se ha desplazado a la búsqueda de perspectivas sociopsicológicas propias de los estudios de recepción. Incluso más allá de las posiciones recepcionistas clásicas, trata la recepción del programa como transformación consecutiva o divergente de la orientación socio-política del programa. La aceptación o la modificación de lo recibido y su difusión renovada caracteriza la interacción, la participación más activa, también en las mediaciones digitales de la comunicación.

De acuerdo con el marco y los principios propuestos, el discurso mediático comunicado en el programa de debate se define por la coherencia o divergencia entre los temas propuestos por la dirección con las manifestaciones de los invitados en relación con la muestra de opiniones de los espectadores en los mensajes publicados.

Para establecer la agenda directiva propuesta en esos programas se analizan por separado las intervenciones de los distintos participantes. Se establece la relevancia alcanzada de un modo similar al juicio del público que al final del programa vota decidiendo qué contertulio ha ganado y por tanto "se lleva el gato al agua".

Cada programa comienza por una entrevista en la que el director-presentador propone los temas con sus preguntas y el/la entrevistado/da establece el marco de los asuntos para esa noche. El resto de invitados puede ampliar o desplazar los asuntos de interés que más tarde se toman como referencia en las intervenciones de los participantes en el debate en directo, y luego son aludidas por los mensajes telefónicos sobreimpresos en pantalla.

El diálogo interpersonal entre el director-presentador y el entrevistado presenta el discurso de actualidad y las temáticas del día al público en plató o en casa. Desde el punto de vista de los espectadores la entrevista pasa a diálogo (Donnelly y otros, 2010) y la comunicación es tríada en algunos análisis recientes de discurso televisivo. El análisis de las preguntas planteadas al entrevistado y a los invitados al debate debe determinar si la dirección prevista para el programa define los parámetros del discurso que finalmente se recibe y se transforma en el plató y en los mensajes en la pantalla. Si la principal eficiencia se considera en los medios, la apertura de temas del programa se entiende como focalizadora del resto de intervenciones de los distintos participantes en cada programa. Como el discurso mediático no es tan poderoso y unívoco se enriquece en los programas hablados con la riqueza de la variedad de los intervinientes. 
Las ampliaciones o propuestas del entrevistado a las preguntas de apertura fijan la agenda inicial del programa. Las pautas de la dirección en las preguntas ampliadas por entrevistado y tertulianos terminan por fijar los asuntos efectivamente tratados durante cada programa. A partir del discurso propuesto desde las pautas de la dirección se habla de públicos construidos por los medios.

Sin embargo si la dirección se apoya en las sugerencias y orientaciones de los invitados y entrevistado para conectar con lo compartido por una comunidad, se entiende que el programa busca un nicho de audiencia preexistente, quizá con carácter de comunidad. Puede que incluso se plantee una comunicación tan abierta con su público como para contar con sus iniciativas; en este caso el mismo programa se entiende como comunitario.

En resumen, el entrevistado puede ser altavoz de la dirección y la dirección enfocar la actualidad según las perspectivas de los invitados o bien se orienta explícitamente a expectativas y valores compartidos por la comunidad de espectadores.

La entrevista dura media hora, el debate con invitados que la continúa ocupa el resto del programa hasta la una de la madrugada. De nuevo en el debate vuelve a participar el director como moderador, cediendo unos turnos de palabra más cortos y animando a la participación de los cinco invitados. Este segundo diálogo representado, el más extenso, puede construir un discurso grupal enlazado o no con los acuerdos o las propuestas de la entrevista que abre el programa. Para su análisis se comparan las propuestas y posiciones en torno a los temas abiertos o ampliados anteriormente en la entrevista.

Hoy parecen más adecuadas las técnicas analíticas del discurso en cuanto a la atención a diferentes agentes, así como a sus formas y contenidos en la interlocución. Porque la comunicación diferencia personalidades y posicionamientos como debe esclarecer acuerdos y coincidencias. Como se puede comprender, no se pueden igualar interlocutores tan diferentes como el/a entrevistado/a, los debatientes o tertulianos y los espectadores autores de mensajes visualizados o los votantes del público en el "gatómetro".

Cada uno de los participantes en el debate que sigue a la entrevista, durante las siguientes dos horas, dispone de menos tiempo de intervención que la persona entrevistada, pero puede reforzar o contradecir los puntos de vista del resto de los tertulianos interpelados por las preguntas del moderador que dirige el programa. El tipo de los tertulianos es comparable a los de otras tertulias de la noche con algún invitado discrepante menos cercano a la línea editorial del programa que mantiene el aire de la anterior tertulia radiofónica y con un elenco delimitado de posibles invitados.

El tercer tiempo de intervención, el tiempo del público, es el más breve y fragmentario de los tres tipos de participaciones en el debate televisado. No es comunicación interpersonal como la de la entrevista, ni comunicación grupal como algunos momentos del debate. La publicación de mensajes es recortada y dispersa, se trata de una comunicación mediada, 
como otras comunicaciones digitales en los chats o los foros... y refleja rasgos cercanos a formas fluidas de comunidades como las virtuales en internet.

Las opiniones del medio millón de espectadores diarios disponen de una breve representación en el millar de mensajes publicados durante las cincos noches del debate televisado. Como se explica en los objetivos se persigue compararlos con el discurso propuesto por el programa, comprobar si la respuesta de los espectadores que consiguen insertar sus mensajes es afín y continuista por el poder del medio o más bien es amplificadora y en algún sentido divergente por la propia riqueza comunal.

Se cuentan como mensajes los saludos a vecinos de una localidad o las felicitaciones al programa. No se conoce el número de mensajes rechazados ni los criterios de admisión de comunicados durante el periodo analizado. Se analizan y agrupan los contenidos explícitos en cada mensaje y se relacionan con los temas propuestos por presentador e invitados durante cada uno de los programas del debate estudiado. Los temas de los mensajes no pueden abarcar todos los intereses de la audiencia. Su análisis debe indicar si el elenco temático es más amplio en el programa o en la audiencia y en qué medida se pueden considerar coincidentes los temas propuestos por el programa con los intereses expresados por parte de la audiencia esos días de junio de 2010 seleccionados.

Para evaluar la afinidad o divergencia con los temas propuestos en cada programa se han analizado y comparado los contenidos explícitos en las transcripciones de los mensajes. Las posiciones explícitas de la parte de público que alcanza publicar sus mensajes durante los programas de la muestra, se gradúan según los contenidos sean reiterativos, amplificadores, complementarios o divergentes.

Esta escala considera receptores puros a quienes refuerzan el mismo mensaje del programa. El público amplificador es aquel que refiere los contenidos explícitos del programa a públicos concretos que puedan estar particularmente interesados en ellos. En relación con la actividad propia de los influenciadores en comunidades, detallan y ajustan a públicos determinados la misma orientación temática del programa. Se consideran públicos complementarios, aquellos afines que como los usuarios activos y creativos en internet, ejercen de emisores de mensajes que añaden valor informativo en el mismo tono y orientación de los mensajes del debate televisado. Por fin, los públicos críticos son aquella parte de la audiencia menos afín a la orientación del programa que consigue expresar esas divergencias entre los mensajes aprobados para ser emitidos durante el programa.

Como se detalla, el principio de este apartado metodológico, el análisis del carácter comunitario mostrado en los SMS del público del programa, pretende situarse entre los estudios cualitativos de la recepción por la audiencia mediática y las investigaciones de usuarios de comunidades virtuales, por ejemplo de tipo etnográfico, alrededor de determinadas series o programas. La tecnología del mensaje de texto sobreimpreso como faldón de las imágenes del debate separa dos activi- 
dades de recepción. En su diálogo con la imagen del momento, permite mostrar la afinidad o divergencia de quienes opinan o comentan lo que se ha dicho o mostrado poco antes. También es un espacio en el que se producen interlocuciones externas con otros espectadores, como los saludos antes mencionados.

Estas muestras de la comunicación del público con un programa de radio o de televisión a través de mensajes de texto han representado sólo una etapa intermedia, tanto en el apoyo a la financiación de la producción como en las formas de construcción de una comunidad digital. Aunque desaparecidas deben ser recordadas por su clara definición de la muestra de opiniones del público, independientes de otros criterios muestrales en investigaciones de comunicación. Dentro de los estudios de recepción ofrece más información de la audiencia que el envío de votos a un medio o la comunicación en un grupo por llamadas perdidas. Todavía no alcanza grados de interacción superiores o intercambios característicos de la comunicación interpersonal en las comunidades de espectadores en el portal web de un cadena o en la página en Facebook de los programas de medios de comunicación. Desde la muestra de mensajes admitidos en el programa no se pueden distinguir grupos y divergencias.

Sin embargo interesa también por sus relaciones con otros estudios más actuales de comunicación fragmentada casi sincrónica como las actuales investigaciones sobre Twitter. Para participar desde la audiencia hoy el programa de "El gato al agua" como otros programas ya dispone de una comunidad en línea más en los estándares de bidireccionalidad de la comunicación en la segunda década de internet (web 2.0). Tras el registro, los usuarios conectados en el momento, no solo pueden votar una de las dos respuestas al tema del día (el gatómetro) o enviar comentarios y sugerencias. Ahora disponen de opciones mucho más amplias que la carta, la llamada o el mensaje de texto desde un teléfono móvil. Desde la información en los propios perfiles se puede conocer la información de otros miembros en la comunidad con los que es posible intercambiar información no directamente relacionado con un episodio concreto del programa que reune la comunidad (Rheingold, 1996).

\section{Resultados}

\subsection{Propuesta de discurso desde la presentación y la entrevista inicial}

En el análisis del alcance del proyecto de temas propuestos por la dirección durante los cinco programas, se confirma la definición política y crítica del gobierno, que le caracteriza y el poder de sus propuestas sobre invitados y emisores de mensajes publicados. El estilo de dirección del conductor del programa Antonio Jiménez no es directo. En sus intervenciones no refuerza directamente la orientación dominante que aparece ampliamente respaldada por invitados y público. Sin embargo, la actualidad de la huelga que rodea la muestra seleccionada, crece en el discurso de estos días y llega a dominar la agenda de temas de la dirección el último programa de la muestra. 
La dirección del programa sólo ha incentivado con la orientación de sus preguntas los temas que los invitados han configurado como agenda político-económica de los cinco programas de esa semana. En todos ellos además los temas más mencionados han sido la reforma laboral, la corrupción en el PSOE, el caso Gürtel y el estado del país por la crisis económica.

Sobre los invitados habituales y ocasionales del debate ha dominado la orientación de los temas de cada noche a partir de cuatro de los cinco seleccionados para la entrevista. En el primer programa de la muestra, la entrevistada es Esperanza Aguirre, que subraya las deficiencias que encuentra en la reforma laboral del Gobierno y abre la orientación de la crítica en el resto del debate, también con menciones en días siguientes. El segundo día la entrevista no ejerce de fuente principal de la agenda de la noche. En el programa del 3 de junio la crítica a la gestión de la crisis económica de los tertulianos sigue siendo el discurso central a pesar de haber comenzado con una entrevista centrada en las desigualdades autonómicas a instancia del presidente de la Comunidad Autónoma riojana, el invitado de ese día.

El tercer entrevistado en la muestra es autor de un libro denuncia sobre las mentiras del Presidente del Gobierno. Consigue extender sus opiniones, sobre la defensa de un diputado socialista invitado entre los tertulianos y contestado por el resto de debatientes. De nuevo la crítica política enfoca el cuarto programa analizado, de acuerdo con la impronta de una dirección que impuso el tema de la crítica a la gestión económica; por encima de cuestiones de la reforma laboral y del caso Bono apuntados por el entrevistado de ese día y seguido también débilmente por alguna intervención de tertulianos.

Conforme se acerca el día de la huelga convocada por los sindicatos, el peso de la conversación pública se percibe en los SMS del público destacando incluso por encima de la crisis económica, que de nuevo era la orientación preferente del programa según las intervenciones del director-moderador. Incluso por encima de la corrupción en el gobierno que se repetía como propuesta atendiendo al entrevistado del quinto último día de la muestra.

En resumen, la orientación de las conversaciones desde los entrevistados encauza las propuestas temáticas de la dirección del programa asentando el tono y los temas en más de la mitad de los días. Las dos excepciones en que los debatientes recuperan temas del momento y no los de los entrevistados, no implican un cambio de agenda y recuperan la focalización general del discurso.

La dirección del programa no da muestras de percibir el interés creciente de los mensajes en la actualidad, en la huelga general que se propone.

A lo largo de la semana crece un ruido casi paralelo que no altera la orientación temática del programa. Un ejemplo de esta descoordinación queda ejemplificada en el programa del día 7, centrada en la crítica de medidas económicas por el director del programa, atenuando el interés por temas de corrupción que también se suscitan y al margen de la mayoría de mensajes referidos a la huelga. 
Tabla I. Participaciones: Aportaciones sobre los temas más mencionados

\begin{tabular}{|c|c|}
\hline & Participaciones \\
\hline Reforma laboral & 134 \\
\hline Corrupción en el PSOE & 99 \\
\hline Crisis económica & 54 \\
\hline Caso Gürtel & 52 \\
\hline Caso Bono & 48 \\
\hline Huelga general & 33 \\
\hline Ejército en actos religiosos & 32 \\
\hline Cambio gobierno & 28 \\
\hline Uso indebido propaganda & 27 \\
\hline Ley del aborto & 10 \\
\hline Sexo menores & 6 \\
\hline Sector Automóvil & 6 \\
\hline Sanidad prohíbe fumar & 5 \\
\hline Mentiras Rubalcaba & 5 \\
\hline Desigualdad CA & 4 \\
\hline A favor toros & 2 \\
\hline Mala gestión exterior & 2 \\
\hline Riesgo pensiones & 2 \\
\hline
\end{tabular}

Fuente: Elaboración propia

\subsection{El tertuliano favorito. Desarrollo de la agenda del programa en los debatientes}

En la segunda fase de construcción mediática del discurso se incorporan las aportaciones de los debatientes a los temas principales del discurso en cada uno de los días grabados. Se trata de un análisis de las intervenciones de cada uno de los invitados y de sus interacciones tanto con los entrevistados antes como con los mensajes emitidos de espectadores. Las votaciones del público premian a quien "se lleva el gato al agua", el argumentador favorito para el público votante. 
En la muestra analizada coincide un perfil de ganador sólido, consistente en sus convicciones, en general muy participante y activo. Sólo uno de los ganadores ha tenido una participación más discreta, en el programa del día 1 de junio. El resto de ganadores figuran además entre los principales participantes, asiduos en estos debates televisados.

En el primer programa de junio de 2010, el segundo de esa semana, ya está introducida la crítica de la reforma laboral ampliamente debatida por tertulianos y audiencia tras la entrevista a Esperanza Aguirre. Además de la frecuencia de menciones, el argumentario, las anécdotas y testimonios refuerzan un abanico de alternativas y técnicas completamente integradas en la más amplia disputa de este momento de seria crisis económica.

Tabla II. temas relacionados con la orientación de los programas

\begin{tabular}{|c|c|c|c|c|c|c|}
\hline & Huelga general & A favor toros & \begin{tabular}{|l} 
Contra la \\
prohibición del \\
Ejército en \\
eventos religiosos
\end{tabular} & $\begin{array}{l}\text { Contra la } \\
\text { recomendación } \\
\text { de sexo a } \\
\text { menores } \\
\end{array}$ & Ley del aborto & $\begin{array}{l}\text { Sanidad prohíbe } \\
\text { fumar en espacios } \\
\text { públicos }\end{array}$ \\
\hline 1 de junio & 0 & 0 & 0 & 0 & 24 & 0 \\
\hline 2 de junio & 18 & 0 & 0 & 0 & 0 & 5 \\
\hline 3 de junio & 0 & 0 & 125 & 11 & 0 & 0 \\
\hline 4 de junio & 28 & 0 & 0 & 0 & 0 & 0 \\
\hline 7 de junio & 226 & 5 & 0 & 0 & 0 & 0 \\
\hline
\end{tabular}

Fuente: Elaboración propia

Con salpicaduras de crítica al gobierno socialista, los términos y referencias en el segundo programa confirman estas ideas como eje del discurso del programa. La personificación de la crisis en el presidente español sólo abre algunos turnos defensa del participante socialista en el debate. 
Tabla III. temas políticos en los programas

\begin{tabular}{|l|l|l|l|l|l|l|l|}
\hline & $\begin{array}{l}\text { Caso } \\
\text { Bono }\end{array}$ & Caso Gürtel & $\begin{array}{l}\text { Corrup- } \\
\text { ción PSOE }\end{array}$ & $\begin{array}{l}\text { Desigualdad } \\
\text { entre } \\
\text { Comunidades } \\
\text { Autónomas }\end{array}$ & $\begin{array}{l}\text { Mentiras } \\
\text { Rubalcaba } \\
\text { peración entre } \\
\text { política exterior y el } \\
\text { gobierno }\end{array}$ & $\begin{array}{l}\text { Uso indebido } \\
\text { de propa- } \\
\text { ganda }\end{array}$ \\
\hline 1 de junio & 0 & 0 & 66 & 0 & 0 & 0 & 28 \\
\hline 2 de junio & 51 & 12 & 0 & 9 & 5 & 0 & 0 \\
\hline 3 de junio & 0 & 13 & 71 & 0 & 0 & 0 & 0 \\
\hline 4 de junio & 39 & 42 & 0 & 0 & 0 & 2 & 0 \\
\hline 7 de junio & 0 & 0 & 43 & 0 & 0 & 0 & 0 \\
\hline
\end{tabular}

Fuente: Elaboración propia

Un tema secundario en el discurso de programa protagoniza el interés y el tiempo de intervenciones en el programa del día 3 de junio. En concreto la prohibición al ejército para participar en actos religiosos, por parte del Ministerio de Defensa. Esta gestión gubernamental de la multiculturalidad creciente en España genera una indignación importante tanto en entre algunos de los invitados como en una parte relevante de los mensajes transmitidos. Se trata de un tema político, pero también social. La cantidad de mensajes emitidos (127 SMS) en apoyo de los militares que se oponen a la medida es, a la vez signo de la existencia de comunidades diferenciadas en el público del programa. Por encima de la participación en los temas propuestos por el programa se genera un flujo paralelo de comunicaciones sobre los actos religiosos en las celebraciones nacionales. La dirección no atiende ni ese día ni los siguientes a la agenda de algunas comunidades del público y mantiene como eje la inacción gubernativa ante la crisis económica y en tal sentido se refuerzan las opiniones vertidas por entrevistados e invitados al debate. 
Tabla IV. temas sociales en los programas

\begin{tabular}{|l|l|l|l|}
\hline & Crisis económica & Reforma laboral & Riesgo de pensiones \\
\hline 1 de junio & 50 & 93 & 0 \\
\hline 2 de junio & 57 & 14 & 6 \\
\hline 3 de junio & 0 & 57 & 12 \\
\hline 4 de junio & 178 & 19 & 0 \\
\hline 7 de junio & 57 & 24 & 0 \\
\hline
\end{tabular}

Fuente: Elaboración propia

El programa del viernes 4 de junio, sin entrevistado y sólo de dos horas de duración, cierra la semana confirmando los parámetros principales del discurso del programa reflejado y seguido por la mayor parte de las intervenciones del público en pantalla (178 SMS).

Por fin el lunes siguiente 7 de junio, en víspera de convocatoria oficial de la huelga general por los sindicatos, el programa registró 226 llamadas a la movilización y el programa se hace eco de esta importante participación de la audiencia. Los tertulianos recogen el tema y discuten sobre las formas de proceder con la crisis en otros países. esta apertura reduce en parte la crítica a gobierno que se mantiene muy mencionado y como segundo eje del discurso del programa recogido y aceptado, al menos por aquella muestra de espectadores que envían sus mensajes y aparecen publicados en durante las horas del debate nocturno.

\subsection{Los temas del público en los mensajes. Perfiles de participación de los autores de mensajes}

La divergencia de los intereses de los debatientes con respecto al invitado entrevistado en dos de los cinco días no modifica la agenda de temas que propone el programa y sólo destaca otros asuntos anteriormente propuestos.

Los dos días en que se observan divergencias de los mensajes del público con respecto a los temas propuestos revelan aspectos de comunidades paralelas, sean preexistentes o no a su fidelización en este programa. Por el número de mensajes desviados del discurso principal y por la definición de rasgos patrióticos o manifestaciones religiosas se puede reconocer, aunque no demostrar, la existencia de comunidades que comparten valores y símbolos.

Sólo en el último día de la muestra los tertulianos reconducen el debate dando protagonismo a la huelga. Los temas de los mensajes que se pueden atribuir a más amplias comunidades sociales, que se enfrentaron al decreto de actos laicos por parte del Estado no fueron introducidos en el debate a pesar de contar con una elevada tasa de participación. 
En el resto de la muestra y en el conjunto del análisis, los mensajes emitidos del público completan y amplifican los temas del programa. Destaca la definición ideológica y la concordancia entre dirección y votaciones o muestras de mensajes del público en un discurso, con unas cifras minúsculas de crítica o diferencia.

Los cierres del discurso, en la muestra de mensajes son en general coincidentes con el comportamiento de un público en un medio de masas. El día 1 de junio los mensajes mostrados no coinciden con los temas predominantes de los tertulianos o de la entrevistada, aunque apoyan en la pregunta del gatómetro el adelanto de elecciones generales. El día 2 sí que hay coincidencia entre el tema más tratado en la tertulia y la mayoría de mensajes publicados. El día 3 en la tertulia no se siguen los temas del debate y la mayoría de los mensajes atacó la prohibición al ejército de participar en actos religiosos. El 4 de junio los temas del programa y los mensajes publicados de nuevo construyen un discurso cohesionado. El día 7 los mensajes se refieren a la huelga convocada a pesar de que el tema más tratado por los tertulianos fue la crisis económica.

Desconociendo los mensajes eliminados por incumplir el protocolo o por otros motivos, se muestra una audiencia uniforme y constante. Parte de esta audiencia representada en los mensajes refuerza el discurso dominante con información complementaria y matizaciones según muestra la tabla siguiente:

Tabla V. Perfiles de participación en los mensajes de texto de una semana en porcentajes

\begin{tabular}{|l|l|l|l|l|l|l|}
\hline Perfiles /día & 1 junio & 2 junio & 3 junio & 4 junio & 7 junio & total \\
\hline Reiterativos & 47.9 & 50.5 & 40.3 & 38.6 & 61.9 & 49.4 \\
\hline Amplificadores & 12.5 & 26.3 & 21.7 & 36.8 & 9.8 & 20.4 \\
\hline Complementarios & 33 & 23.3 & 37.1 & 24.4 & 27.2 & 28.5 \\
\hline Críticos & 6.5 & 0 & 0.8 & 0 & 1.02 & 1.6 \\
\hline Total \% SMS / semana & 18,37 & 10.9 & 13.6 & 24.7 & 32,3 & $100=909 S M S$ \\
\hline
\end{tabular}

Fuente: Elaboración propia, universo 909 mensajes de texto.

Saludos y agradecimientos se han consideran mensajes reiterativos del discurso de los programas. En concordancia con lo que expresan más o menos la mitad de los mensajes emitidos.

Un 20\% de los participantes que publican sus mensajes refuerzan el tono o el sentimiento, y en consecuencia amplifican, al menos en su esfera de influencia, la difusión de su información. Pero se trata de información de nuevo concordante con la impronta mediática establecida desde el presentador y sus invitados.

Según los distintos sentidos de público y de comunidad de los que se parta (véase la introducción) se pueden considerar, cuando menos, público interesado a los espectadores que publican mensajes añadiendo información o formación en sus 
mensajes publicados. Hay una cifra considerable en la muestra que detalla, focaliza o argumenta en sentidos complementarios con respecto al tratamiento del tema en el plató del programa. El incremento de valor que supone la información añadida, los ejemplos diversos o argumentaciones complementarias aparecen en un $28 \%$ de los mensajes visualizados durante las emisiones de los cinco programas.

Apenas hay espectadores críticos de este programa que hagan llegar sus diferencias a los mensajes mostrados.

\section{Conclusiones}

1. Desde la dirección de "El gato al agua”, en el canal de televisión del grupo de comunicación Intereconomía se organiza un programa de debate en el que, como en su predecesor La Espuela, unos invitados y analistas comentan la situación político-económica desde una posición de crítica al segundo gobierno del socialista Rodríguez Zapatero. Alcanza una significativa audiencia entre los talk shows de los canales digitales terrestres en prime time, completando la franja nocturna de la programación de esta cadena. Unos doscientos mensajes diarios exhibidos durante las más de dos horas de duración de la entrevista y el posterior debate expresan su agrado con la orientación editorial del programa. Dependiendo del rango de alcance que se conceda a esta muestra se puede tomar como una cata confirmatoria de la capacidad de este programa de convocar una audiencia repetida como que se puede reconocer como público habitual del programa. La satisfacción con el estilo y la argumentación del tertuliano que se lleva el gato al agua muestra que la dirección acierta en la elección de sus colaboradores, algunos heredados del programa de radio que le precedió. Tanto "La Espuela" como "El gato al agua" son programas que han construido un público asiduo con unos rasgos compartidos en su visión de la economía y de la situación política.

En el estudio de cinco programas realizado se confirma una dirección eficaz a la hora de presentar y preguntar por temas, que son finalmente focalizados por entrevistados y debatientes, en síntonía con el parecer y el sentir común de su público habitual. La actualidad de la huelga general podía introducir un factor de distracción o un cambio en la agenda de asuntos para el programa, pero no afecta a la dirección del programa en la muestra del programa analizada. Sólo pasa a cuestión de interés tras una masiva recepción de mensajes de texto del público.

2. Por lo que se refiere a la orientación del discurso del programa desde el debate, la moderación supera las intervenciones de los invitados estableciendo el tema y el tratamiento de la crítica a la reforma laboral por encima de las intervenciones de los invitados en uno de los programas. En el resto de programas los debates han conservado el tono y la orientación de las preguntas del presentador al entrevistado de cada día. La propuesta del programa constituye un discurso homogéneo, expresado por distintas voces incluidas las de algún invitado del partido socialista cuya actuación se critica. En los últimos programas se observa una conversación paralela aunque no divergente con 
la tertulia que tiene lugar en el plató. No se trata de un discurso alternativo o contrario. Pero sí más amplio que las temáticas propuestas en la agenda de esos cinco días.

3. La voz coincidente del público expresada en la masiva votación del tertuliano que "se lleva el gato al agua" puede ser más explícita a través del análisis de la comunicación con públicos. El favor del público se ha inclinado en la muestra hacia tertulianos de perfil consistente, pero no destacando a los más participativos ni los más beligerantes. En los días revisados, el perfil moderado en el tono pero contundente en sus afirmaciones es el que gana la mayoría de votos concedidos para El Gato. Tiene que mostrar cierta actividad visible para que pueda entrar en la liza de los favoritos. Salvo algún convidad pro gubernamental, son mayoritariamente concordantes con la dirección del programa, como es frecuente en muchas otras tertulias políticas de los medios españoles. El más votado no aporta matices ni diferencias a este tipo de programa. Desde el punto de vista de la dirección del programa el debatiente ofrece interesantes criterios sobre el estilo de moderación que la audiencia manifiesta a los programadores y productores.

En los mensajes que admite publicar cada programa destaca una autoría de baja interacción, con mensajes continuistas de lo expuesto por invitados y tertulianos. Esta confirmación del estilo y tono del programa para la mayoría de la audiencia que se expresa en los mensajes revela además un importante porcentaje de interlocutores informados que añaden información y argumentos a los asuntos debatidos.

4. Los participantes del público a través de mensajes telefónicos manifiestan una amplia coincidencia con la orientación del discurso propuesto por el programa. El discurso del público coincide en la dirección de temas propuesta desde los invitados al programa. En alguno de los programas se ha producido un diálogo paralelo que sugiere otros intereses y valores compartidos distintos o más sentidos que los que comentaban los tertulianos. Con vistas a la gestión de comunidades en programas de televisión estas u otras fuentes con microinformaciones deben ser analizadas para conocer al menos a las principales comunidades que manifiestan sus sentidos y valores compartidos en cortos mensajes.

La amplia mayoría de mensajes reiterativos o amplificadores corresponden a la caracterización de la audiencia como público propio de un programa de televisión. No manifiesta si se trata de una opinión pública producida por este tipo de programa. Sin duda sí se puede considerar como mantenedor de las opiniones que expresa.

Resultan muy poco significativos los mensajes contrarios o críticos, contando con que puede haber más, ya que se trata además de una entrada filtrada en principio por límites de protocolo de participación. Esta uniformidad de públicos se puede comparar con los estudios que afirman el posicionamiento político de los grupos de comunicación en España. 
5. Una parte de los mensajes no sólo refuerza el tono del programa sino que lo complementa con testimonios y ejemplos además de la resonancia afectiva ya mencionada en la conclusión anterior. Este público además de motivado cuenta con una representación de participantes informados que la dirección del programa podría tener más en cuenta para la programación y decisiones sobre su agenda de temas. Aunque la muestra de autores de mensajes de texto publicados no puede ser representativa, sí es significativo que el medio pueda contar con colaboradores externos cuya participación ocasional es importante en el paso de públicos a comunidades de un programa.

El previsible destino de muchos programas en plataformas digitales se ha confirmado en el caso del "El Gato al Agua". Ya cuenta desde hace meses con su propia comunidad virtual en el portal de la cadena y en una página en Facebook. Las redes sociales propias o generalistas facilitan espacios más amplios y personalizados en los que además de la construcción de públicos heterogéneos los programas se pueden comunicar y relacionar con comunidades de interés. La dirección web actual de esta comunidad: http://www.intereconomia.com/programa/gato-al-agua.

El mensaje de texto mantiene bastantes limitaciones de asincronía, espacio de mensaje, interacción... con respecto a la comunicación en redes digitales. Ese enriquecimiento de la comunicación televisiva con la web 2.0 termina incidiendo en la concepción, producción y dirección de los programas, como también altera los rasgos clásicos de los públicos y de las comunidades por efecto de la extensión y frecuencia de las actuales prácticas de comunicación en redes digitales. Es utópica y quizá no sostenible una participación abierta y una construcción colectiva de discursos sociales. Pero carecen de perspectivas de futuro las rutinas mediáticas de baja interacción y el cultivo de audiencias desinformadas y pasivas. En cualquier caso, con las redes sociales no se puede programar de espaldas a la audiencia y sin dar cabida a las comunidades que forman los públicos del presente que puedan sostener los medios del futuro.

\section{Anexos}

\section{Anexo I: Temas tratados en los 5 programas}

De carácter social

Aborto

Huelga general

Labor de los sindicatos

Sobre la prohibición de fumar

Prohibición de participación del ejército en actos religiosos 
Sexo en menores

De carácter político

Corrupción

Conveniencia de cambio de gobierno

Caso Bono

Caso Gurtell

Desigualdad en el trato a las CC.AA. por parte del gobierno central

Actuaciones del ministro Rubalcaba

Veracidad del presidente del Gobierno

Actuación de Carod Rovira

Política exterior del gobierno

Sobre la conveniencia de adelanto de elecciones

De carácter económico

Crisis económica

Reforma laboral

Pensiones

Sector automóvil

\section{Anexo II: Ficha de cada programa}

1 de junio de 2009

\section{PARTICIPANTES}

Moderador: Antonio Jiménez

Invitada: Esperanza Aguirre. Presidenta de la Comunidad de Madrid

Tertulianos:

Federico Quevedo: periodista El Confidencial.com

Jaime González: Jefe de opinión de ABC

Isabel Durán: periodista 
Raimundo Castro: periodista

Alfonso Rojo: periodista. Periodistadigital.com

Pregunta del gatómetro:

¿Creen ustedes que Zapatero aguantará hasta agotar la legislatura en 2012?

SÍ: 44 ' $8 \%$

NO: $55^{\prime} 2 \%$

Ganador del Gato: Federico Quevedo

1. Federico Quevedo: $47 \%$

2. Isabel Durán: $21 \%$

3. Alfonso Rojo: $15 \%$

4. Jaime González: 13\%

5. Raimundo Castro: $2 \%$

2 de junio de 2009

PARTICIPANTES

Moderador: Antonio Jiménez

Invitado: Pedro Sanz: presidente de la CC.AA. de La Rioja (media hora)

Tertulianos:

Miguel Durán: abogado

Cristina Alberdi: abogada, ex ministra del gobierno de Felipe González

Román Cendoya: periodista

Pablo Castellano: abogado

Ignacio Gil Lázaro: diputado del PP

Pregunta del gatómetro:

¿Creen que la gestión de la crisis por parte de Zapatero ha puesto en riesgo las pensiones?

SÍ: 65 '9\%

NO: 34 '1\%

Ganador del Gato: Román Cendoya 30\%

$168\left|n^{\circ} 14\right|$ doxa.comunicación 
1. Román Cendoya: $30 \%$

2. Pablo Castellano: $25 \%$

3. Miguel Durán: 20\%

4. Ignacio Gil Lázaro: 20\%

5. Cristina Alberdi: 5\%

3 de junio de 2009

PARTICIPANTES:

Moderador: Antonio Jiménez

Invitado: José Ma Zavala: periodista y escritor

Tertulianos:

Antonio Miguel Carmona: profesor de macroeconomía

José $\mathrm{M}^{\mathrm{a}}$ Carrascal: periodista

Jaime González: jefe de opinión de ABC

José Antonio Segurado: presidente de Segurado y Galobat

Eduardo García Serrano: periodista

Pregunta del gatómetro: ¿Están de acuerdo con recortar la participación del ejército en actos religiosos?

SÍ: 18 '2\%

NO: 81 ' $8 \%$

Ganador del Gato: Eduardo García Serrano 34\%

Eduardo García Serrano: 34\%

Jaime González: 32\%

José Antonio Segurado: 13\%

José María Carrascal: 11\%

Antonio Miguel Carmona: 6\%

4 de junio de 2009

PARTICIPANTES: 
Moderador: Antonio Jiménez

Invitado: Gustavo Arístegui

Tertulianos:

Esther Jaén: periodista

Rubén Múgica: abogado (ex militante del PSE, ahora de UpyD)

Antonio Martín Beaumont: El Semanal digital

Fernando Vizcaíno1: abogado laboralista

Chimo Ortega2: Director Área motor grupo Intereconomía

7 de junio de 2009

PARTICIPANTES:

Moderador: Antonio Jiménez

Invitado: Carlos Floriano secretario de comunicación del PP (media hora)

Tertulianos:

José $\mathrm{M}^{\mathrm{a}}$ Carrascal: periodista

Juan Iranzo: Director del IEE

Carlos Dávila: Director de La Gaceta

Alfredo Dagnino: presidente de la Fundación Universitaria San Pablo CEU

Miguel Arias Cañete: diputado del PP

Pregunta del gatómetro: ¿Están a favor de que se convoquen elecciones generales ya?

SÍ: 78 ' $8 \%$

NO: $20{ }^{\prime} 2 \%$

Ganador del Gato: Alfredo Dagnino 35\%

Alfredo Dagnino: 35\%

Juan Iranzo: 22\%

Carlos Dávila: 16\%

José Ma Carrascal: $12 \%$

Miguel Arias Cañete: $12 \%$

$170 \mid n^{\circ} 14$ | doxa.comunicación 


\section{Referencias bibliográficas}

Almirón, N. (2009): “Grupos privados propietarios de medios de comunicación en España: principales datos estructurales y financieros”, Comunicación y Sociedad, XXII, pp. 243-263.

Averweg, U. R. y Leanin, M. A. (2011): "Visions of Community”, Information Technologies \& International Development, Summer, 7, 2, pp. 17-30.

Beyer, Y.; Enli, G. S. ; Maasø, A. J.; Ytreberg, E (2007): “Small Talk Makes a Big Difference: Recent Developments in Interactive, SMS-Based Television”, en Television New Media, 8, 3, pp. 213-234.

Birks, J. (2010): "Press protest and publics: The agency of publics in newspaper campaigns", Discourse \& Communication, 4, 1, pp. 51-67.

Corominas, M. (2001): “Los estudios de recepción en línea: Portal de la Comunicación”, InCom-UAB > Aula abierta: Lecciones del Portal: Disponible en: http://www.portalcomunicacion.com [Consultado el: 14/02/2011]

Dafonte Gómez, A. (2010): "Reflexiones teóricas en torno al concepto de género y a las dificultades que plantea su aplicación en la investigación sobre contenidos televisivos" en Comunicación y Sociedad, XXIII, 1, 2010, pp. 121-152.

Dijk, T. A. van (2008): “Semántica del discurso e ideología”, Discurso \& Sociedad, 2 (1) 2008 [1995], pp. 201-261.

Donnelly, R., Harvey, J. y O'Rourke, K. (2010): Critical design and effective tools for e-learning in higher education: theory into practice. New York: IGI Global, 2010.

Downing, J. (2001): Radical Media. Disponible en: http://web.mit.edu/schock/www/docs/radical_media.pdf. [Consultado el: $14 / 02 / 2011]$

Estudio General de Medios (2010): Datos de la tercera oleada del año móvil 2010. Asociación para la investigación de medios de comunicación (AIMC). Disponible en: http://www.aimc.es. [Consultado el: 14/02/2011]

Facebook del Grupo Intereconomía. Disponible en: http://www.facebook.com/gatoalagua. [Consultado el: 14/11/2011]

Fiske, J. (1987): Television Culture. Londres-Nueva York: Methuen, en Corominas, M. (2001): “Los estudios de recepción”, Portal de la Comunicación InCom-UAB > Aula abierta: Lecciones del Portal: Disponible en: http:/ /www.portalcomunicacion.com/esp/n_aab_lec_3.asp?id_llico=4\&index=0 [Consultado el: 14/02/2011]

Gandy Jr., O. H. (2000): “Audience Construction: Race, Ethnicity and Segmentation in Popular Media”. Paper submitted to the Popular Communication Division 50th Annual Conference of the International Communication Association, May 2000.

Gordon, J. (ed.) (2009) Notions of Community: A Collection of Community Media Debates and Dilemmas. Oxford: Peter Lang.

Gutiérrez Rubí, A. (2001): Generación APPS = Generación ON. [blog post 29 nov 2011]. Disponible en: http://www.gutierrez-rubi.es/2011/11/28/generacion-apps-generacion-on [Consultado el: 29/11/2011] 
Hardy, C. (2004): "Scaling Up and Bearing Down in Discourse Analysis. Questions Regarding Textual Agencies and their Context”, Organization, 11 (3), pp. 415-425. Disponible en: http://org.sagepub.com/content/11/3/415.full.pdf. [Consultado el: 14/02/2011]

Hartmann, M. (2008): “La mirada etnográfica sobre el medio móvil” en Aguado Terrón, J. M. y Martínez Martínez, I. (eds) Sociedad móvil: tecnología, identidad y cultura coord. Barcelona: Biblioteca Nueva.

Hutchby, I. (2006): Media talk: conversation analysis and the study of broadcasting. McGraw-Hill International.

Intereconomía.com (s/d) Portal web del grupo de comunicación Intereconomía. Disponible en: http://www.intereconomia.com/programa/gato-al-agua. [Consultado el: 14/11/2011]

Jankowski, N. W (2002): Community media in the information age: perspectives and prospects. Cresskill: Hampton Press.

Jankowski, N. W. (2006): “Creating Communities with Media: History, Theories and Scientific Investigations”, en Lievrouw, L. A. y Livingstone S. M.: Handbook of New Media: social shaping and social consequences of ICTs. London - New York: Sage.

Livingstone, S. y Lunt, P. K. (1991): Talk on television: audience participation and public debate. London: Routledge.

Livingstone, S. M. (ed). (2005): “Audiences and publics; when cultural engagement matters for the public sphere", Changing Media: Changing Europe. Cultural Studies, Intellect Books.

Mautner, G. (2005): Time to get wired: Using web-based corpora in critical discourse analysis, Discourse \& Society, 16 (6), pp. 809-828.

Martí Pellón, D. (2008): “Autores iberoamericanos en las tradiciones y postmodernidad de la comunicación”, Razón y Palabra, 61. Disponible en: http://www.razonypalabra.org.mx/n61/varia/dmarti.html [Consultado el: 14/02/2011]

Martínez Nicolás, M. y Saperas Lapiedra, E. (2011): “La investigación sobre Comunicación en España (1998-2007). Análisis de los artículos publicados en revistas científicas”, en Revista Latina de Comunicación Social, 66, pp. 101-129. Disponible en: http://www.revistalatinacs.org/11/art/926_Vicalvaro/05_Nicolas.html. [Consultado el: 14/02/2011]

Meneses Araujo, J. P. (2010): A rádio em crise antes da crise provocada pela Internet. Radio in crisis before radio crisis caused by Internet. Observatorio (OBS*) Journal, 4 (1), pp. 01-24.

Míguez González, M I. (2010): Los públicos en las relaciones públicas. Barcelona: Editorial UOC.

Monge, B. S. y Olabarri Fernández, M. E. (2011): “Los alumnos de la UPV/EHU frente a Tuenti y Facebook: usos y percepciones”, Revista Latina de Comunicación Social, 66, pp. 79-100. Disponible en: http://www.revistalatinacs.org/11/ art/925_UPV/04_Monge.html. [Consultado el: 14/02/2011]

Museum of Broadcast Communications: (s/f) (Talk Show). Disponible en: http://www.museum.tv/eotvsection.php?entrycode=talkshows [Consultado el: 14/02/2011]

Orozco Gómez, G. (1991): “La audiencia frente a la pantalla”, en Orozco Gómez, G. (2005), Televidencia: perspectivas para el análisis de los procesos de recepción televisiva. Universidad Iberoamericana. 
Ruíz-Mafé, C.; Sanz-Blas, S.; Fernando Tavera, J. (2010): “Análisis de los factores determinantes del uso de mensajes SMS para participar en programas de televisión”, Cuadernos de Gestión, 10, 2, pp. 117-132.

Pinho Neto, J. A. de Sá (2010): Informação e sociabilidade nas comunidades virtuais: um estudo sobre o Orkut. Documento de trabajo de investigación. Disponible en: http://dci2.ccsa.ufpb.br:8080

Pew Internet (2010): Mobile access. Disponible en: http://pewinternet.org/Reports/2010/Mobile-Access-2010.aspx?r=1 [Consultado el: 14/02/2011]

Rheingold, Howard (1996): Virtual Communities. Disponible en: http://www.rheingold.com/vc/book/. [Consultado el: 14/02/2011]

Thompson, J. B. (2005): “The New Visibility”, Papers, 78, pp. 11-29.

Turow, J. (2005): "Audience Construction and Culture Production: Marketing Surveillance in the Digital Age", The ANNALS of the American Academy of Political and Social Science, January, 597, 1, pp. 103-121. Disponible en: http://ann.sagepub.com/content/597/1/103.full.pdf+html [Consultado el: 14/02/2011]

Soriano, J. (2007): Las nuevas reglas de la etnografía de la comunicación. Lección en el Portal InCom. Disponible en: http://www.portalcomunicacion.com/esp/n_aab_lec_1.asp?id_llico=30 [Consultado el: 14/02/2011]

Verdú, V. (2007): Yo y Tú, objetos de lujo. El personismo: la primera revolución cultural del siglo XXI. Barcelona: DeBolsillo.

- (2008): Passé composé. Madrid: Alfaguara. Cfr. Noguera, J. M. y Bañuls, F.

- (2009): Esbozo del individuo en red: la identidad retial y el personismo en Vicente Verdú. Disponible en línea: http://www.perio.unlp.edu.ar/question/files/noguerayotro_1_ensayos_24primavera2009.htm. [Consultado el: $14 / 02 / 2011]$

Ytreberg, E (2009): “Extended liveness and eventfulness in multi-platform reality formats”, New Media \& Society, June, 11, 4, pp. 467-485. Disponible en: http://nms.sagepub.com/content/11/4/467.full.pdf+html [Consultado el: 14/02/2011] 